\title{
Lusioersily
}

\section{Synergistic toughening and electrical functionalization of an epoxy using MWCNTs and silane- /plasma-activated basalt fibers}

Ralph, C., Quan, D., Moloney, P., Carolan, D., Abourayana, H., Ivankovic, A., Dowling, D., \& Murphy, N. (2021). Synergistic toughening and electrical functionalization of an epoxy using MWCNTs and silane-/plasma-activated basalt fibers. Journal of Applied Polymer Science, 138(1), [49605]. https://doi.org/10.1002/app.49605

Link to publication record in Ulster University Research Portal

Published in:

Journal of Applied Polymer Science

Publication Status:

Published (in print/issue): 05/01/2021

DOI:

10.1002/app.49605

\section{Document Version}

Author Accepted version

\section{General rights}

Copyright for the publications made accessible via Ulster University's Research Portal is retained by the author(s) and / or other copyright owners and it is a condition of accessing these publications that users recognise and abide by the legal requirements associated with these rights.

\section{Take down policy}

The Research Portal is Ulster University's institutional repository that provides access to Ulster's research outputs. Every effort has been made to ensure that content in the Research Portal does not infringe any person's rights, or applicable UK laws. If you discover content in the Research Portal that you believe breaches copyright or violates any law, please contact pure-support@ulster.ac.uk. 


\title{
Synergistic toughening and electrical functionalization of an epoxy using MWCNTs and silane-/plasma-activated basalt fibres
}

Dong Quana, Peter Moloneyb, Declan Carolanc,d, Hisham Abourayanab, Calvin Ralphe, Alojz Ivankovicb, Denis Dowlingb, Neal Murphyb

aStructural Integrity \& Composites Group, Faculty of Aerospace Engineering, Delft University of Technology, 2629HS, Delft, Netherlands

bSchool of Mechanical and Materials Engineering, University College Dublin, Dublin 4, Ireland cDepartment of Mechanical Engineering, Imperial College London, London, SW7 2AZ, UK dFAC Technology, London, SW18 4LW, UK eSchool of Engineering, Ulster University, Belfast, BT37 0QB, UK Correspondence to: Neal Murphy (E-mail: neal.murphy@ucd.ie)

\begin{abstract}
This work studied the effects of adding short basalt fibres (BFs) and multi-walled carbon nanotubes (MWCNTs), both separately and in combination, on the mechanical properties, fracture toughness and electrical conductivity of an epoxy polymer. The surfaces of the short BFs were either treated by silane coupling agent or further functionalised by atmospheric plasma to enhance the adhesion between the BFs and the epoxy. The results of a single fibre fragmentation test demonstrated a significantly improved BF/epoxy adhesion upon applying the plasma treatment to the BFs. This resulted in better mechanical properties and fracture toughness of the composites containing the plasma-activated BFs. The improved BF/epoxy adhesion also affected the hybrid toughening performance of the BFs and MWCNTs. In particular, synergistic toughening effects were observed when the plasma-activated BFs/MWCNTs hybrid modifiers were used, while only additive toughening effects occurred for the silane-sized BFs/MWCNTs hybrid modifiers. This work demonstrated a potential to develop strong, tough and electrically conductive epoxy composites by adding hybrid BF/MWCNT modifiers.
\end{abstract}




\section{INTRODUCTION}

Epoxy resins are widely used as both structural adhesives and matrices of fibre reinforced polymer composites due to their desirable engineering properties, i.e. high stiffness, high strength, good thermal stability and excellent chemical and corrosion resistance. However, epoxies possess inherently low fracture toughness which limits their usefulness in the unmodified form. Blending second phase modifiers, such as rubber particles1-4, silica particles5-8, carbon nanomaterials9-12, nanoclay13-15 and short fibres16-18 into epoxies is a well-established method to improve their fracture performance. Moreover, the addition of different modifiers to the epoxies can also introduce other desirable functional properties, such as good electrical and thermal conductivities, high electrical insulation and outstanding fire retardancy.

Extensive research has been performed to study the effects of adding chopped fibres, including short carbon fibres (CFs), short glass fibres (GFs) and short basalt fibres (BFs), on the mechanical properties and fracture toughness of epoxies 16,19,20,21. For example, Dong et al.16 reported that the incorporation of $3 \mathrm{wt} . \%$ CFs into an epoxy polymer increased the fracture toughness and flexural strength by $36 \%$ and $25 \%$, respectively. Kaynak et al.19 observed that the addition of 3 wt. $\%$ short CFs (6 mm long) into an epoxy resin increased the flexural modulus and impact toughness by $37 \%$ and $20 \%$, respectively. Further improvements were achieved when additional surface treatment was applied to the CFs. Kim20 used $6 \mathrm{~mm}$ long BFs as modifiers to enhance an epoxy resin, and reported an increase of above $200 \%$ in the flexural strength due to the addition of $10 \mathrm{wt} . \%$ BFs. In another study, Chen et al.22 observed that the shear modulus and absorption energy (measured from a V-notched rail shear test) significantly increased by $48 \%$ and $231 \%$, respectively upon 
adding 30 vol. $\%$ BFs (with an average length of $3 \mathrm{~mm}$ ) into an epoxy. Arikan et al.21 reported significant improvements in the elastic modulus and impact toughness of an epoxy resin due to the addition of $6 \mathrm{~mm}$ long GFs. It was proved that the application of a surface-modification to the short GFs using a silane coupling agent further increased the elastic modulus and fracture toughness of the epoxy composites. Overall, it is generally accepted that the addition of these short fibres can significantly improve the mechanical and fracture properties of epoxies23, and the adhesion between the fibres and the epoxies plays a critical role in the toughening performance19, 21.

Nano-scale additives, such as rubber nanoparticles1, silica nanoparticles6, graphene 10 and carbon nanotubes11, were also widely used as epoxy toughening agents. Carbon nanotubes (CNTs) are attractive candidates as modifier materials for the toughening and modification of epoxies, due to their outstanding properties, i.e. high aspect ratio of up to several thousands, excellent electrical conductivity and high mechanical properties. In general, adding a small amount of CNTs into the epoxies should clearly improve their mechanical properties and fracture toughness 24,25 . However, the toughening performance of CNTs was well below the expectation, due to the poor dispersion ability of the CNTs and the weak adhesion at the epoxy/CNTs interface25. To date, the most prevalent methods for dispersing CNT into epoxies are high shear mixing26, three roll milling 10 , solution mixing 27 and ultra-sonication 28 mixing. Nevertheless, these methods are still limited to processing epoxy nanocomposites with a low content of CNTs to obtain reasonably good dispersion. A number of review articles summarised the research work related to CNT-modified epoxies $24,25,29,30,31$, from where, the following conclusions could be drawn. Firstly, blending a small amount of CNTs into the epoxies had a beneficial effect on the mechanical properties and fracture toughness. However, adverse effects occurred as the concentration of CNTs increases 
above $0.5 \mathrm{wt} . \%-1 \mathrm{wt} . \%$ (the actual value depends on the materials, processing method and surface functionalization) due to the agglomeration of the CNTs. Secondly, the toughening level of CNTs was much lower than that of the other nano-additives, such as rubber nanoparticles, silica nanoparticles and nanoclays. Gojny et al.24 reported that the maximum improvements in the strength, stiffness and fracture toughness of an epoxy by adding CNTs were $10 \%, 15 \%$ and $43 \%$, respectively, obtained at a CNT loading of $0.5 \mathrm{wt} . \%$. Encouragingly, apart from enhancing the mechanical properties, the incorporation of CNTs into epoxies had shown some promise for improving the electrical conductivities9, 32, 33. For example, an ultra-low electrical percolation threshold (defined as the filler content to achieve a conductivity of $\sigma \geq 10-6 \mathrm{~S} / \mathrm{m}$ ) of below $0.1 \mathrm{wt} . \%$ for an epoxy/CNT nanocomposite was reported by Gojny et al.32.

More recently, further research has been carried out into the performance of advance epoxy-based composites toughened by a hybrid combination of both nano-scale CNTs and millimetre-scale short fibres $34,35,36$. Rahmanian et al. 35 managed to grow CNTs on the surface of CFs through a chemical vapour deposition method, and then used the CNT-grown CFs to reinforce an epoxy resin. It was reported that the addition of $1 \mathrm{wt} . \%$ CNT-grown CFs increased the Young's modulus, tensile strength and impact toughness of the epoxy by $17 \%, 21 \%$ and $38 \%$, respectively. Gbadeyan et al.36 reported that the addition of CFs into an epoxy significantly improved the tribological and mechanical properties. Moreover, the addition of $0.1 \mathrm{wt} . \%$ CNTs into the CF-modified epoxies resulted in further remarkable improvements in these properties. Zhang et al.34 studied the effects of adding multi-scale $\mathrm{CF} / \mathrm{CNT}$ modifiers on the mechanical, fracture and impact performance of an epoxy34, and observed a maximum improvement of $67 \%, 28 \%, 220 \%$ and $325 \%$ in the tensile modulus, tensile strength, fracture toughness and impact strength, respectively, upon adding 10 wt.\% CFs and a small amount of (between 0.5-1 wt.\%) CNTs. Based on the literature review, it is 
clear that the addition of multi-scale CNTs and short fibres is an attractive method to enhance and functionalise epoxy polymers. Moreover, the short CFs debonded and pulled-out during the fracture process, without causing any damage to the fibres themselves. This indicated that the adhesion between the CFs and the epoxy was not sufficiently high to fully utilise the excellent mechanical properties of the short CFs, irrespective of the surface treatment methods studied. Accordingly, it is conceivable that the cheaper GFs and BFs possessing a relatively lower grade of mechanical properties are attractive alternatives to the CFs for epoxy multi-scale toughening, provided that appropriate surface treatments are applied. However, to date, the majority of studies have focused on the use of CFs for hybrid modification, while the GFs and BFs have received less attention.

This work aims to study the effects of adding BFs and multi-walled carbon nanotubes (MWCNTs) on the mechanical, fracture and electrical properties of an epoxy resin. The main novelty is that the surfaces of the silane-coated BFs were further activated by applying an atmospheric plasma treatment, which resulted in a much higher level of adhesion between the BFs and the epoxy, and subsequently significantly affected the mechanical and fracture behaviour of the epoxy composites. The results demonstrated that strong, tough and electrically conductive epoxy composites could be achieved by blending hybrid BF/MWCNT modifiers into the epoxy, and a good BF/epoxy adhesion was required to get synergistic toughening effects.

\section{EXPERIMENTAL}

\section{Materials}

The epoxy resin was a standard diglycidyl ether of bisphenol-A (DGEBA) with an epoxide equivalent weight of 185 g/eq, (Araldite LY556) supplied by Huntsman, UK. The hardener was poly (propylene glycol) bis (2-aminopropyl ether) with an amine hydrogen equivalent weight of 
$60 \mathrm{~g} / \mathrm{eq}$, purchased from Sigma-Aldrich. The curing schedule for this system was $75{ }^{\circ} \mathrm{C}$ for $3 \mathrm{~h}$ with a post cure at $110{ }^{\circ} \mathrm{C}$ for an additional $12 \mathrm{~h}$. The MWCNTs were obtained in a powder form from Graphene Supermarket, USA. They appeared in an entangled cotton-like form. These nanotubes had an average outer diameter of $50-85 \mathrm{~nm}$ and a length of $10-15 \mu \mathrm{m}$. The short BFs, MBCF13SS03, were supplied by Mafic, Ireland. They were sized using a proprietary silane solution. The length and diameter of the fibres were $3 \mathrm{~mm}$ and $13 \mu \mathrm{m}$, respectively. The same type of basalt fibre but in a long form was also supplied by Mafic, Ireland for a single fibre fragmentation test.

\section{Sample Preparation}

An in-house pilot-scale barrel atmospheric plasma reactor37, as shown in Figure 1, was used to active the surface of the silane-sized BFs. The plasma reactor consists of a quartz chamber with effective treatment dimensions of $20 \mathrm{~cm}$ length and $7 \mathrm{~cm}$ inner diameter. A $1500 \mathrm{~W}$ high voltage power source (from Plasma Technics Inc., USA) was used to generate the plasma. The output power was controlled by varying the percent ON time $v s$. OFF time (pulse density modulation (PDM) \%) from $1 \%$ to $100 \%$. The high voltage power source was directly connected to two aluminium rods, which acted as the biased and earthed electrodes. The aluminium rods were also used to rotate the quartz chamber in order to agitate the basalt fibre during the treatment. A helium and oxygen gas mixture with a flow rate of $10 \mathrm{slm}$ and $0.2 \mathrm{slm}$, respectively was used as the processing gases. The chamber was purged for 2 minutes with helium, while rotating the basalt fibres, prior to the plasma ignition. In this work, $50 \mathrm{~g}$ short BFs were placed in the quartz chamber and the plasma operated at $60 \%$ PDM for 3 mins. The chemical composition on the surfaces of the silane-coated and plasma-treated BFs were analysed using an X-Ray photoelectron spectrometer (XPS, Kratos Axis Ultra DLD), equipped with Al Ka (1486.7 eV) X-ray source. The 
results are shown in Table 1. It was found that the application of an atmospheric plasma treatment to the surfaces of silane-coated BFs decreased the amount of carbon element from $81.49 \%$ to $65.63 \%$, and increased the oxygen element from $16.36 \%$ to $26.23 \%$. This corresponded to a decrease of the $\mathrm{C}: \mathrm{O}$ ratio from 4.98 to 2.50 , and subsequently improved the adhesion between the epoxy matrix and the BFs, as will be confirmed later on.

A high shear mixing process was employed to disperse the MWCNTs into the epoxy. Firstly, the MWCNTs/epoxy resin mixture was pre-mixed under vacuum using an IKA RW20 mixer operating at $600 \mathrm{rpm}$ for $1 \mathrm{~h}$ at approx. $50{ }^{\circ} \mathrm{C}$. The relatively high temperature reduced the viscosity of the mixture for easier processing. The MWCNTs/epoxy resin mixture was then further processed using a Silverson L4RT shear mixer at 2000rpm for $1 \mathrm{~h}$ at approximately $50{ }^{\circ} \mathrm{C}$, followed by another $2 \mathrm{~h}$ shear mixing at $2000 \mathrm{rpm}$ with the temperature gradually reduced to $5{ }^{\circ} \mathrm{C}$. By reducing the temperature in this way, a viscous system at relatively low temperatures could generate sufficient shear forces to effectively break up MWCNT agglomerates. The mixture was then thoroughly degassed in a vacuum oven at $80{ }^{\circ} \mathrm{C}$. This mixing procedure was optimised after various trials. The final mixture appeared homogeneous with the MWCNTs well dispersed. A stoichiometric amount of hardener was added to the MWCNTs/epoxy resin mixture, and then further mixed under vacuum for another 30 mins at $600 \mathrm{rpm}$ using the IKA RW20 mixer. Finally, the mixture was cast into an aluminium mould for curing in a rotating oven. To disperse the BFs in the epoxy, the BFs/epoxy resin mixture was firstly mixed under vacuum using the IKA RW20 mixer operating at $600 \mathrm{rpm}$ for $1.5 \mathrm{~h}$ at room temperature. Then, a stoichiometric amount of hardener was added into the mixture followed by a further 30 min vacuum mixing before the final curing. To manufacture the epoxy composites with hybrid BFs/MWCNTs fillers, the MWCNTs were firstly dispersed into the epoxy resin using the shear mixing process. The BFs were then 
blended into the MWCNT/epoxy resin mixture. It is noteworthy that the curing of the mixture took place immediately after the mixing process for all the composites. This is to prevent the formation of excessive MWCNT agglomerates before gelation of the epoxy resin. Throughout the remainder of this paper, the epoxy matrices modified with basalt fibres are designated by the acronym ' $\mathrm{BFx}$ ', where ' $x$ ' denotes the weight percentage of the fibres, those modified solely with multi-wall carbon nanotubes are denoted by 'MWCNTy', where ' $y$ ' denotes the weight percentage of MWCNTs, and the hybrid systems are denoted by 'BFx-MWCNTy'. If the surface treatment of the BFs is discussed, the acronym BFs(S) stands for the silane coupling agent treated BFs and BFs $(\mathrm{P})$ stands for the plasma treated BFs, i.e. the code BF3-MWCNT0.5 represents an epoxy composite modified with $3 \%$ BFs and $0.5 \%$ MWCNTs, and BF3(P)-MWCNT0.5 specifically indicates that the BFs were plasma treated.

\section{Experimental methods}

The dispersion of the BFs and the MWCNTs was investigated using a transmission optical microscope (TOM, Nikon E80i (Orina)). The cured samples were ground and fine polished to thin sections according to the technique described in reference 38 . The thickness of the samples was approximately $50 \mu \mathrm{m}$ for checking the dispersion of the MWCNTs and approximately $2.5 \mathrm{~mm}$ for investigating the dispersion of the BFs.

In order to roughly measure the length of the MWCNTs after the high shear mixing, some uncured epoxy/MWCNTs mixture was dissolved in acetone, and then placed in a low energy ultrasonic bath for $1 \mathrm{~h}$ vibration. A small amount of the solution with remaining MWCNTs was dropped onto a piece of aluminium foil. After the acetone was fully evaporated, a scanning electron microscope 
equipped with a field emission gun (SEM, FEI Quanta 3D) was used to image the MWCNTs on the aluminium foil.

A single fibre fragmentation test was used to measure the interfacial shear strength (IFSS) between the BFs and the epoxy matrix. Typical dog-bone shaped samples were prepared by fixing a single fibre axially in the resin matrix. The test was performed using a Deben micro dual leadscrew tensile stage with a crosshead speed of $0.03 \mathrm{~mm} / \mathrm{min}$, until the fibres fractured into several fragments. The tensile stage was mounted on an Olympus BX53 microscope, equipped with an X-Y stage and linear polarising filters, which was used to perform measurements on fibre diameter and broken fragment lengths. During the test, strain cycles of $0.2 \%$ increments were used with the number of breaks recorded for each cycle. The IFSS was estimated according to the Kelly and Tyson model 39 :

$$
\tau=\frac{\sigma_{f} d}{2 l_{c}}
$$

where $d$ is the fibre diameter, $l_{c}$ is the critical fibre length and $\sigma_{f}$ is the fibre strength at the critical fibre length. $l_{c}$ is calculated by:

$$
l_{c}=\frac{4}{3} \bar{l}
$$

where $\bar{l}$ is the average fibre length. The fibre strength at the critical length was calculated by tensile testing single fibres at gauge lengths of 25, 50 and $100 \mathrm{~mm}$ according to ASTM D3822 and then using Weibull analysis to predict the fibre strength at the critical fibre length.

The Young's modulus and yield strength of the epoxy composites were measured using the uniaxial compression test according to ASTM D695. The compressive yield strength was defined 
as the first point on the stress-strain curve where an increase in strain was not accompanied by a corresponding increase in stress. Tetragonal shaped specimens with dimension of $5 \mathrm{~mm} \times 5 \mathrm{~mm}$ $\times 10 \mathrm{~mm}$ were machined from a cured plate. The tests were conducted at a loading rate of 1 $\mathrm{mm} / \mathrm{min}$ at room temperature.

The fracture toughness of the polymer composites was determined using a single edge notch threepoint bend (3PB) test following the guidelines of ASTM D5045-99. The dimension of the samples was $6 \mathrm{~mm} \times 12 \mathrm{~mm} \times 60 \mathrm{~mm}$. A sharp pre-crack was introduced by tapping a liquid nitrogen chilled razor blade into a V-notch. The tests were conducted at room temperature with a constant displacement rate of $1 \mathrm{~mm} / \mathrm{min}$. The fracture toughness, KIC, values were calculated using:

$$
K_{I C}=\frac{P}{B W^{\frac{1}{2}}} f\left(\frac{a}{W}\right)
$$

where $P$ is the critical load, $B$ is the sample thickness, $W$ is the specimen width and $a$ is length of the pre-crack. $f(a / W)$ is dimensionless function. The fracture energy, GIC, was calculated using the well-known relation:

$$
G_{I C}=\frac{K_{I C}^{2}}{E}\left(1-v^{2}\right)
$$

where $E$ is the tensile Young's modulus and $v$ is Poisson's ratio of the epoxy taken as 0.361 .

The fracture surfaces of the 3PB specimens were studied using the SEM under an acceleration voltage of $5 \mathrm{kV}$. The samples were gold sputter coated at a current of $30 \mathrm{~mA}$ for 15 seconds to obtain an approximately $5 \mathrm{~nm}$ thick gold layer. 
The electrical conductivity of the epoxy composites containing MWCNTs was measured using a four-probe method in a Keithley 2400 SourceMeter under voltage-source testing mode. Samples were prepared by coating a sample of dimension $12 \mathrm{~mm} \times 20 \mathrm{~mm} \times 2 \mathrm{~mm}$ with a conductive silver paint to reduce the contact resistance.

\section{RESULTS AND DISCUSSION}

\section{Morphology}

Representative TOM images of the cured epoxy composites are presented in Figure 2, to give an indication of the dispersion characteristics of the BFs and the MWCNTs in the epoxy. From Figures $2(\mathrm{a}-\mathrm{c})$, it is clear that in-plane random orientation of the BFs was achieved for the epoxy composites filled with solely BFs. Figures 2 (d-f) show reasonably good dispersion of MWCNTs in the MWCNT-modified epoxy composites. The dark regions in these micrographs are locations with a high MWCNT content while the lighter areas represent resin-rich regions. The alternating pattern of resin-rich and nanotube-rich regions is typical in epoxies modified with CNTs and has been observed previously9. Agglomerates of MWCNTs were observed in all cases, and more pronounced agglomerates were noted for the composites filled with a higher loading of MWCNTs. Finally, an indication of the dispersion of the MWCNTs in the hybrid composites is given in Figures 2 (g-i). It should be noted that the different surface treatments of the BFs, i.e. silane-sized or plasma-activated, exhibited an unnoticeable effect on the dispersion of the BFs and the MWCNTs in the composites. A comparison of Figures 2 (d-f) with Figures 2 (g-i) shows a slightly increased level of agglomeration of the MWCNTs due to the addition of the BFs to the MWCNTmodified epoxies, evidenced by the larger area of the dark regions in Figures 2 (g-i).

An example SEM micrograph of the remaining MWCNTs after removing the epoxy matrix is shown in Figure 3. The average lengths of the MWCNTs were measured using a java-based image 
software, ImageJ, based on approximately 100 measurements in each case. The inset shows a typical measurement of the length of one MWCNT, by dividing the curved MWCNT into a number of segments. The average lengths of the MWCNTs were roughly measured to be $4.6 \pm 2.1 \mu \mathrm{m}, 3.6$ $\pm 2.6 \mu \mathrm{m}$ and $4.1 \pm 2.4 \mu \mathrm{m}$ for MWCNT0.3, MWCNT0.5 and MWCNT0.8, respectively. They were much shorter than the as-received MWCNTs, i.e. 10-15 $\mu \mathrm{m}$. Severe damage to the MWCNTs upon applying a high shear mixing process within the epoxy is typical and was also reported in the literature $40,41$.

\section{Interfacial shear strength}

Figure 4 (a) shows representative optical microscope images of the single fibre fragmentation test samples under polarised light. It was found that obvious birefringence patterns occurred around the broken BFs for both the silane-sized BFs and the plasma-activated BFs, indicating stress concentration around the break points of the BFs. Moreover, the break-point intervals were much shorter for the plasma-activated BFs than the silane-sized BFs. This indicated a stronger interfacial adhesion with the epoxy for the plasma-activated BFs42. Figure 4 (b) shows the IFSS between the BFs and the epoxy matrix. The IFSS between the BFs and the epoxy matrix was measured to be 33.7 MPa for the silane-sized BFs. The application of the plasma treatment to the BFs significantly increased the IFSS to $49.4 \mathrm{MPa}$ (by $46.6 \%$ ). The increased level of BF/epoxy adhesion enhanced the load transfer between the BFs and the epoxy matrix, and subsequently improved the mechanical and fracture properties of the epoxy composites.

\section{Mechanical properties}

The measured Young's modulus and yield strength of the epoxy composites are summarised in Figure 5. A value of 2.87 GPa was measured for the Young's modulus of the un-modified epoxy. The addition of $0.3 \%$ MWCNTs notably increased the Young's modulus to $3.31 \mathrm{GPa}$. However, 
no further increase was observed as the loading of the MWCNTs increased. This was mainly attributed to the increasing amount of MWCNT agglomerates as the MWCNT content increased, i.e. the MWCNT agglomerates were poorly bonded together, and subsequently resulted in poor stress transfer between the matrix and the MWCNTs9, 11, 24. Figure 5 shows that the incorporation of $\mathrm{BFs}(\mathrm{S})$ significantly increased the Young's modulus of the epoxies. For example, as the concentration of the $\mathrm{BFs}(\mathrm{S})$ increased from $3 \mathrm{wt} . \%$ to $8 \mathrm{wt} . \%$, the Young's modulus steadily increased from $2.87 \mathrm{GPa}$ of the control epoxy to $4.25 \mathrm{GPa}$ of the $\mathrm{BF}(\mathrm{S}) 8$ composites, and from 3.09 GPa of the MWCNT0.5 composite to $4.12 \mathrm{GPa}$ of the BF(S)8MWCNT0.5 composites. A more prominent increase in the Young's modulus was observed by adding the $\mathrm{BFs}(\mathrm{P})$ to the epoxy in all cases. For example, the Young's modulus was measured to be $5.17 \mathrm{GPa}$ for the $\mathrm{BF}(\mathrm{P}) 8$ composites, which was $21.6 \%$ higher than that of the $\mathrm{BF}(\mathrm{S}) 8$ composite. This resulted from the improved level of adhesion between the BFs and the epoxies (see Figure 4 (b)), that led to more effective stress transfer between the epoxy and the BFs19. The yield strength of the epoxy notably increased due to the incorporation of a small amount of MWCNTs $(0.3 \%)$, and significantly increased as a result of adding the BFs, see Figure 5 (b). As expected, the addition of plasmaactivated BFs also resulted in more remarkable improvements in the yield strength of the epoxies than the silane-sized BFs, owing to the improved BF/epoxy adhesion. For instance, the yield strength of the $\mathrm{BF}(\mathrm{P}) 8$ composite was $12 \%$ higher than that of the $\mathrm{BF}(\mathrm{S}) 8$ composite. Figure 5 clearly suggested that the BFs and MWCNTs worked together to enhance the mechanical properties of the epoxies, i.e. the Young's modulus and yield strength of the composites modified by hybrid BFs/MWCNTs were higher than that of the composites containing solely BFs or MWCNTs. For example, the BF(P)5-MWCNT0.3 formulation measured much higher Young's modulus and yield strength when compared to the $\mathrm{BF}(\mathrm{P}) 5$ composite or the MWCNT0.3 composite. 
However, the agglomeration of the MWCNTs at a relatively high loading of MWCNTs adversely affected the mechanical properties, i.e. the Young's modulus and yield strength of the BF(S)5MWCNT0.8 composite was measured to be slightly lower than that of the $\mathrm{BF}(\mathrm{S}) 5$ composite.

\section{Fracture energy}

The fracture energies (GIC) of the epoxy composites modified by BFs, MWCNTs and their hybrid fillers are shown in Figure 6. A value of $239 \mathrm{~J} / \mathrm{m} 2$ was measured for the fracture energy of the control epoxy. Blending solely MWCNTs into the epoxy resulted in notable increases in the fracture energy, i.e. the addition of $0.3 \mathrm{wt} . \%$ and $0.5 \mathrm{wt} . \%$ MWCNTs into the un-modified epoxy increased the fracture energy to $317 \mathrm{~J} / \mathrm{m}_{2}$ (by $33 \%$ ) and $358 \mathrm{~J} / \mathrm{m}_{2}$ (by $50 \%$ ), respectively. No further improvement in the fracture energy was obtained for a higher concentration of MWCNTs, i.e. $0.8 \%$. This was attributed to the increased level of MWCNT agglomerations $9,24,43$. The incorporation of solely $\mathrm{BFs}(\mathrm{S})$ significantly improved the fracture toughness of the epoxy. The value of GIC increased from $239 \mathrm{~J} / \mathrm{m}_{2}$ of the un-modified epoxy to $559 \mathrm{~J} / \mathrm{m} 2$ (by $134 \%$ ) of the $\mathrm{BF}(\mathrm{S}) 3$ composites, and then to $810 \mathrm{~J} / \mathrm{m} 2$ (by $239 \%$ ) of the $\mathrm{BF}(\mathrm{S}) 5$ composites and further to 962 $\mathrm{J} / \mathrm{m} 2$ (by $303 \%$ ) of the $\mathrm{BF}(\mathrm{S}) 8$ composites. The application of the plasma treatment to the BFs further improved the fracture toughness of the composites, i.e. the values of GIC were measured to be $746 \mathrm{~J} / \mathrm{m}_{2}, 1138 \mathrm{~J} / \mathrm{m}_{2}$ and $1262 \mathrm{~J} / \mathrm{m}_{2}$ for the $\mathrm{BF}(\mathrm{P}) 3, \mathrm{BF}(\mathrm{P}) 5$ and $\mathrm{BF}(\mathrm{P}) 8$ composites, respectively, corresponding to an increase of $33 \%, 40 \%$ and $31 \%$, respectively, when compared to their counterparts containing BF(S)s. The toughening effects of the BFs and the MWCNTs in the hybrid epoxy composites were similar to those observed in the epoxy composites filled with solely BFs or MWCNTs. This means that GIC moderately increased as a result of adding a small amount of MWCNTs to the BF-modified epoxies, and significantly increased due to the addition of BFs to the MWCNT-modified epoxies. In all cases studied, the maximum fracture energy was measured 
to be $1441 \mathrm{~J} / \mathrm{m}_{2}$ for the $\mathrm{BF}(\mathrm{P}) 8-\mathrm{MWCNT} 0.5$ composite, that corresponded to an increase of $341 \%$ when compared to the control epoxy.

To study the hybrid effects of adding BFs and MWCNTs simultaneously into the epoxies, the difference between the toughness improvements of the hybrid-modified epoxies and the epoxies modified with solely BFs or MWCNTs at the same concentration was calculated as:

$$
\Delta\left(\Delta G_{I C\left(B F_{x} M W C N T_{y}\right)}\right)=\Delta G_{I C\left(B F_{x} M W C N T_{y}\right)}-\Delta G_{I C\left(B F_{x}\right)}-\Delta G_{I C\left(M W C N T_{y}\right)}
$$

where $\Delta G I C(X)$ equals to the fracture energy of the $X$ composite subtracted by the fracture energy of the un-modified epoxy. The results of the calculation are shown in Figure 7. Small values of $\Delta\left(\Delta G_{I C}\right)$ were observed for the hybrid-modified composites containing BFs(S) and MWCNTs. This indicates an additive effect of the hybrid modifiers, i.e. the toughening mechanisms of the BFs and MWCNTs contributed separately to the toughening without any noticeable interaction between them. In contrast, the relatively high values of $\Delta(\Delta G I C)$ (varied between $60-125 \mathrm{~J} / \mathrm{m} 2$ in all cases) for the hybrid-modified epoxies containing $\mathrm{BFs}(\mathrm{P})$ and MWCNTs demonstrated a synergistic effect of the hybrid BFs(P)/MWCNTs modifiers. This indicates beneficial interactions between the toughening mechanisms of the BFs(P) and the MWCNTs during the fracture process of the epoxy composites.

\section{Toughening mechanisms}

Representative micrographs of the fracture surfaces of the 3PB specimens are shown in Figure 8. The red arrows indicate the crack growth direction. A smooth fracture surface with a number of river-markings was observed for the control epoxy, see Figure 8 (a). This is typical for brittle epoxies. The addition of MWCNTs in the control epoxy resulted in a much tougher fracture surface, that was identified with more intense river-markings, as shown in Figure 8 (b). SEM images with a higher magnification in Figure 8 (c) shows that a large number of MWCNT segments with 
different lengths, together with many voids at the same scale in size, existed on the fracture surfaces of the MWCNT-modified composites. Similar fracture characteristics were observed in the study44, where the same epoxy resin was toughened by similar concentrations of MWCNTs. The fracture mechanisms of the MWCNTs were concluded to be debonding and pulling-out of the MWCNTs and plastic void growth. It should be noted that the MWCNTs were in a long and nonstraight form in the epoxy, and hence, some of the MWCNTs ruptured rather than pulling-out completely during the fracture process. Moreover, the pull-out of MWCNTs was also associated with some MWCNT bridging, evidenced by the presence of the relatively long MWCNT segments in Figure 8 (c). All of these mechanisms contributed to the energy consumption during the fracture process of MWCNT modified epoxy composites. Figures 8 (d) and (g) present typical fracture surfaces of the composites containing solely BFs. Numerous BFs with different lengths and corresponding holes were observed on the fracture surfaces of both the $\mathrm{BF}(\mathrm{S}) 5$ and $\mathrm{BF}(\mathrm{P}) 5$ composites. Moreover, the average diameter of the holes was measured to be around $16 \mu \mathrm{m}$ based on 20 measurements, that was slightly bigger than the diameter of the BFs, i.e. $13 \mu \mathrm{m}$. Hence, BF pull-out and bridging and plastic void growth took place during the fracture process. It was also found that the fracture surfaces of both the $\mathrm{BF}(\mathrm{S}) 5$ and $\mathrm{BF}(\mathrm{P}) 5$ composites possessed a large number of crack lines, whose amount of was larger for the $\mathrm{BF}(\mathrm{P}) 5$ composites. This resulted from a crack deflection mechanism of the BFs, that, together with fibre pull-out and bridging and plastic void growth, were the main toughening mechanisms of the BFs, as schematically shown in Figure 9. An improved level of adhesion between the BFs and the epoxy matrix upon applying a plasmatreatment to the BFs led to a higher resistance to the pull-out of the BFs and more severe crack deflections during the fracture process, and hence further improved the toughening performance of the BFs. Figures 8 (e) and (h) show typical SEM images of the fracture surfaces of the hybrid 
modified composites, with a focus on the vicinity of the BFs. It was found that the surfaces of the pull-out BFs were very smooth for both the silane-sized and plasma-activated BFs. This indicates an interfacial failure between the BFs and the epoxies during the fracture process, and the BF/epoxy adhesion was not sufficient to generate epoxy failure, in which case, some epoxy matrix should attach on the BFs. However, it is noticeable that the number of micro-size crack deflection lines in the region immediately surrounding the plasma-activated BFs was larger than that of the silane-sized BFs. These phenomena were attributed to the improved interactions between the BFs and the surrounding epoxy matrix upon application of the plasma treatment to the BFs, i.e. a higher level of BF/epoxy adhesion resulted in more efficient stress transfer and redistribution in the surrounding epoxy matrix containing the MWCNTs. Consequently, it could be argued that the BFs cause an increased stress concentration in the regions occupied by the MWCNTs resulting in an increased driving force for debonding and plastic void growth, and a corresponding synergistically greater toughening contribution of the MWCNTs. This was further confirmed by carrying out a closer inspection of the SEM images of the fracture surfaces with a higher magnification, as shown in Figures 8 (f) and (i). It is clear that, when compared with the BF(S)5-MWCNT0.5 composite, the fracture surfaces of the $\mathrm{BF}(\mathrm{P}) 5-\mathrm{MWCNT} 0.5$ composite was relatively rougher and characterised with more complex damage features in the vicinity of the MWCNTs. Moreover, as observed earlier on, a larger amount of crack deflections at micro-scale were obtained for the composites containing $\mathrm{BF}(\mathrm{P}) \mathrm{s}$ than their counterparts modified with $\mathrm{BF}(\mathrm{S}) \mathrm{s}$. A deflected crack path tends to have a fracture surface with a larger total area than a flat crack path, and subsequently includes more nano-scale MWCNTs to introduce their toughening mechanisms for the hybrid modified composites. This was another reason for the significantly improved toughening performance of the hybrid modifiers due to applying the plasma treatment to the BFs. 


\section{Electrical properties}

Figure 10 presents the measured electrical conductivities of the epoxy composites. It was found that the addition of MWCNTs significantly increased the electrical conductivities of the epoxies. For example, the electrical conductivity increased from $2.8 \times 10_{-10} \mathrm{~S} / \mathrm{m}$ for the un-modified epoxy to $6.7 \times 10_{-5} \mathrm{~S} / \mathrm{m}$ for the MWCNT0.3 composite, by approximately five orders of magnitude. This was due to the formation of a percolating network of conductive MWCNTs throughout the composite. The results demonstrated that the percolation threshold, defined as the filler content to achieve a conductivity of above 10-6 S/m, of the MWCNTs for the studied system was below $0.3 \%$. A percolation threshold lower than $0.3 \%$ was also observed in the literature 9,33 . It was found that the subsequent addition of BFs to the MWCNT-modified epoxy nanocomposites slightly decreased the electrical conductivities. It is noteworthy that the reduction in the electrical conductivities was less than one order of magnitude. This was in stark contrast to previously reported results9, 46, where for epoxy nanocomposites that were highly filled with both core-shell rubber particles and MWCNTs and graphene nanoplatelets, a complete loss in electrical conductivity was reported. The loss in electrical conductivities for composites modified with both rubber and nano-carbon materials was attributed to the significant agglomeration of both phases in the hybrid system. The difference in scale between the BFs and MWCNTs in the current work reduced the potential for agglomeration to occur (as shown in Figure 2), and subsequently resulted in a retention of the improvements in the electrical conductivity.

\section{CONCLUSIONS}

In this work, short basalt fibres (BFs) and multi-walled carbon nanotubes (MWCNTs) were blended into an epoxy, in an effort to manufacture enhanced multifunctional epoxy composites. The surfaces of the BFs were treated either by a silane coupling agent or atmospheric plasma. It 
was found that the interfacial shear strengths between the plasma-activated BFs and the epoxy matrix was $46.6 \%$ higher than that between the silane-sized BFs and the epoxy matrix. For this reason, the plasma-activated BFs and their hybrids with MWCNTs were more effective for enhancing the mechanical properties of the epoxies. Moreover, synergistic toughening effects were achieved by blending the plasma-activated BFs and MWCNTs simultaneously into the epoxy, while only additive toughening effects were observed for the hybrid modifiers consisting of silanesized BFs and MWCNTs. The addition of a small amount of MWCNTs moderately increased the mechanical properties and fracture toughness of the composites. However, as the concentration of the MWCNTs increased to 0.8 wt. $\%$, the mechanical properties and fracture energies slightly dropped due to the agglomeration of the MWCNTs. Encouragingly, the incorporation of a small amount of MWCNTs significantly increased the electrical conductivities of the epoxy composites in all cases. Epoxy composites with enhanced electrical conductivity and outstanding mechanical and fracture properties were obtained by blending MWCNTs and BFs simultaneously into the epoxy.

\section{ACKNOWLEDGEMENTS}

The authors gratefully acknowledge the financial support from the Irish Composites Centre. We would also like to thank Mafic (Ireland) for supplying the basalt fibres employed in this study.

\section{REFERENCES AND NOTES}

1. Quan, D.; Ivankovic, A. Polymer 2015, 66, 16-28.

2. Hsieh, T.H.; Kinloch, A.J.; Masania, K.; Lee, J.S.; Taylor, A.C.; Sprenger, S. J. MATER. SCI. 2010, 45, 1193-1210.

3. Abadyan, M.; Bagheri, R.; Kouchakzadeh, M. A. J. Appl. Polym. Sci. 2012, 125, 24672475.

4. Abdollahi, H.; Salimi, A.; Barikani, M. J. Appl. Polym. Sci. 2016, 133, 44061.

5. Dittanet, P.; Pearson, R.A. Polymer 2012, 53, 1890-1905. 
6. Carolan, D.; Ivankovic, A.; Kinloch, A.J.; Sprenger, S.; Taylor, A.C. J. Mater. Sci. 2017, 52, 1767-1788.

7. Maghsoudi, K.; Motahari, S.J. Appl. Polym. Sci. 2018, 135, 45706.

8. Hsieh, T.H.; Kinloch, A.J.; Taylor, A.C.; Sprenger, S. J. Appl. Polym. Sci. 2011, 119, 21352142.

9. Quan, D.; Carolan, D.; Rouge, C.; Murphy, N.; Ivankovic, A. J. Mater. Sci. 2017, 52, 44934508.

10. Lim, Y.J.; Carolan, D.; Taylor, A.C.; J. Mater. Sci. 2016, 51, 8631-8644.

11. Quan, D.; Carolan, D.; Rouge, C.; Murphy, N.; Ivankovic, A. Int. J. Adhes. Adhes. 2018, 81, 21-29.

12. Kavita; Mordina, B.; Tiwari, R.K. J. Appl. Polym. Sci. 2016, 133, 43333.

13. Marouf, B.; Pearson, R.; Bagheri, R. Mat. Sci. Eng. A-Struct. 2009, 515, 49-58.

14. Liu, T.; Tjiu, W.C.; Tong, Y.; He, C.; Goh, S.S.; Chung, T.S. J. Appl. Polym. Sci. 2004, 94, 1236-1244.

15. Mouloud, A.; Cherif, R.; Fellahi, S.; Grohens, Y.; Pillin, I. J. Appl. Polym. Sci. 2012, 124, 4729-4739.

16. Dong, W.; Liu, H.C.; Park, S.J.; Jin, F.L. J. Ind. Eng. Chem. 2014, 20, 1220-1222.

17. Jacob, G.C.; Starbuck, J.M.; Fellers, J.F.; Simunovic, S.; Boeman, R.G. J. Appl. Polym. Sci. 2006, 100, 695-701.

18. Guo, T.; Zhou, Z.; Guo, H.; Xiao, G.; Tang, X.; Peng, M. J. Appl. Polym. Sci. 2014, 131, 41119.

19. Kaynak, C.; Orgun, O.; Tincer, T. Polym. Test. 2005, 24, 455-462.

20. Kim, H. Fiber. and Polym. 2013, 14, 1311-1316.

21. Arikan, A.; Kaynak, D.C.; Tincer, T. Polym. Composite. 2012, 23, 790-805.

22. Chen, J.; Tuo, W.; Wan, C.; Zhang, X. J. Appl. Polym. Sci. 2018, 135, 46078.

23. Zhao, G.; Zhong, J.; Zhang, Y. Recent Patents on Mechanical Engineering 2019, 12, 3-13.

24. Gojny, F.H.; Wichmann, M.H.; Fiedler, B.; Schulte, K. Compos. Sci. and Technol. 2005, 65, 2300-2313.

25. Domun, N.; Hadavinia, H.; Zhang, T.; Sainsbury, T.; Liaghat, G.H.; Vahid, S. Nanoscale 2015, 7, 10294.

26. Quan, D.; Urdaniz, J.L.; Ivankovic, A. Mater. Design 2018, 143, 81-92.

27. Liu, Y.; Wu, H.; Chen, G. Polym. Composite. 2016, 37, 1190-1197.

28. Saswata, B.; Das, A.; Basu, S.; Drzal, L.T. Polym. Composite. 2018, 39, 3119-3128.

29. Liew, K.; Lei, Z.; Zhang, L. Compos. Struct. 2015, 120, 90-97.

30. Mittal, G.; Dhand, V.; Rhee, K.Y.; Park, S.J.; Lee, W.R. J. Ind. Eng. Chem. 2015, 21, 11-25. 
31. Ma, P.C.; Siddiqui, N.A.; Marom, G.; Kim, J.K. Compos. Part A: Appl. S. 2010, 41, 13451367.

32. Gojny, F.H.; Wichmann, M.H.; Fiedler, B.; Kinloch, I.A.; Bauhofer, W.; Windle, A.H.; Schulte, K. Polymer 2006, 47, 2036-2045.

33. Bauhofer, W.; Kovacs, J.Z. Compos. Sci. and Technol. 2009, 69, 1486-1498.

34. Zhang, Z.; Tan, Y.; Wang, X.; Lin, Y.; Wang, L. J. Appl. Polym. Sci. 2016, 133, 43500.

35. Rahmanian, S.; Suraya, A.; Shazed, M.; Zahari, R.; Zainudin, E. Mater. Design 2014, 60, 34-40.

36. Gbadeyan, O.J.; Kanny, K.; Turup Pandurangan, M. J. Tribol.-Trans. ASME. 2017, 140, 022002.

37. Abourayana, H.M.; Dobbyn, P.J.; Whyte, P.; Dowling, D.P. Nanotechnology and Precision Engineering 2019, 2, 1-7.

38. Holik, A.S.; Kambour, R.P.; Fink, D.G.; Hobbs, S.Y. Microstructure Science 1979, 7, 357367.

39. Kelly, A.; Tyson, W.R. J. of Mech. and Phys. Solids 1965, 6, 329-350.

40. Fu, S.Y.; Chen, Z.K.; Hong, s.; Han, C.C.; Carbon 2009, 47, 3192-3200.

41. Sui, G.; Yu,W.; Zhang, Q.; Chen, F.; Fu, Q. Polymer 2017, 123, 65-72.

42. Ageorges, C.; Friedrich, K.; Ye, L. Compos. Sci. and Technol. 1999, 59, 2101-2113.

43. Gojny, F.; Wichmann, M.; Kopke, U.; Fiedler, B.; Schulte, K. Compos. Sci. and Technol. 2004, 64, 2363-2371.

44. Hsieh, T. H.; Kinloch A. J.; Taylor A. C. Kinloch, A. J Mater. Sci. 2011, 46, 7525-7535.

45. Zhang, G.; Karger-Kocsis, J.; Zou, J. Carbon 2010, 48, 4289-4300.

46. Carolan, D.; Ivankovic, A.; Kinloch, A.J.; Sprenger, S.; Taylor, A.C. Polymer 2016, 97, 179-190. 


\section{FIGURES:}

FIGURE 1 A schematic of the barrel atmospheric plasma reactor.

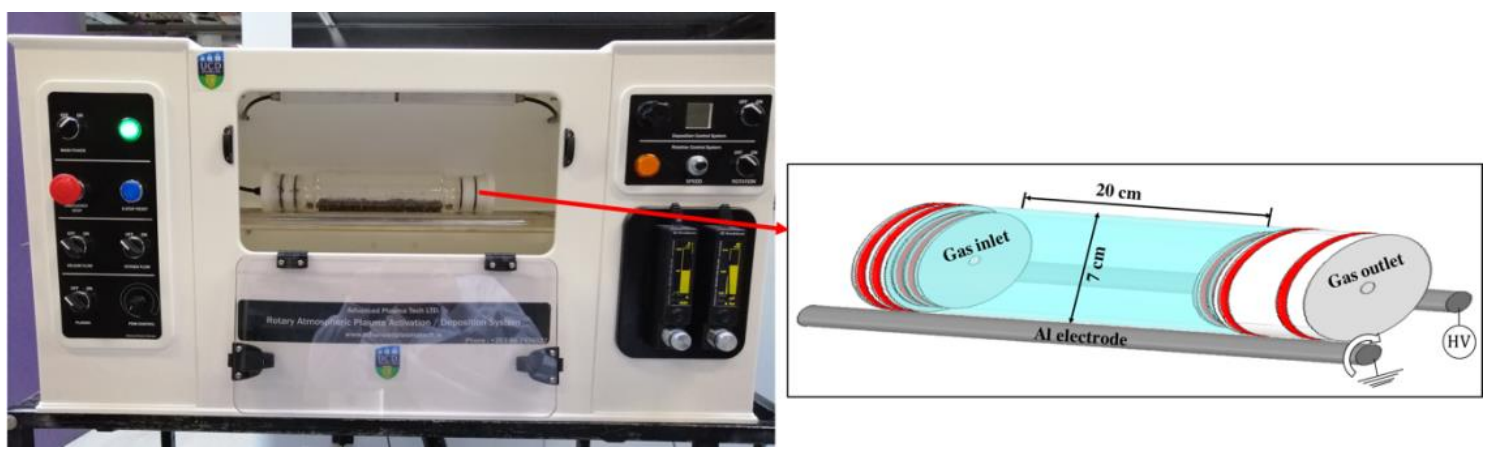

FIGURE 2 Dispersion of the BFs and MWCNTs in cured epoxy composites.

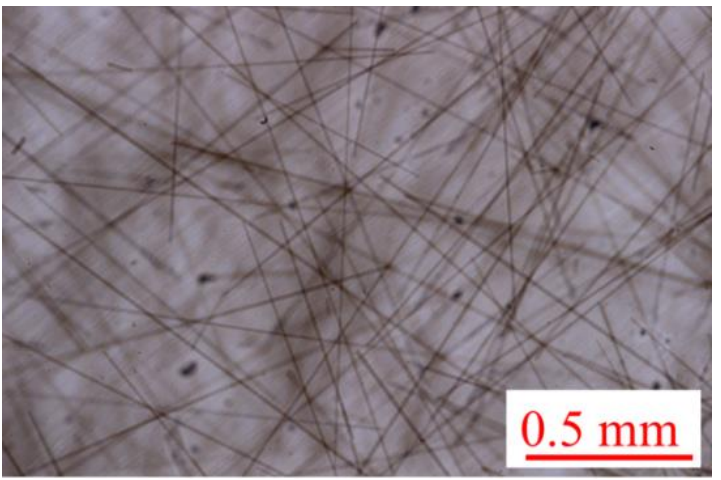

(a) BF3

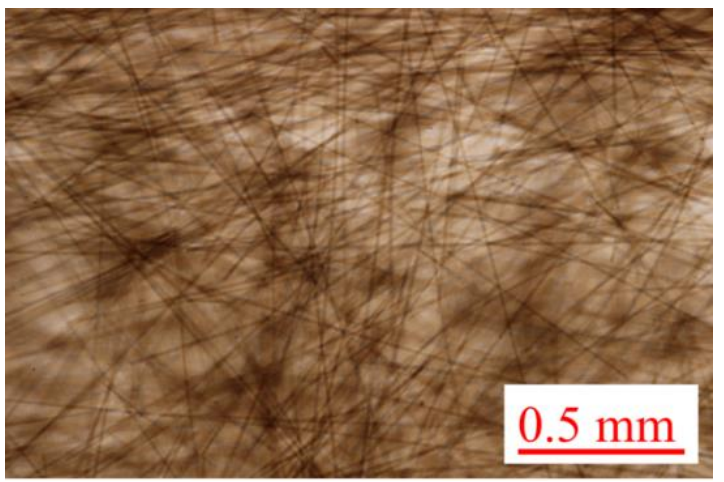

(c) BF8

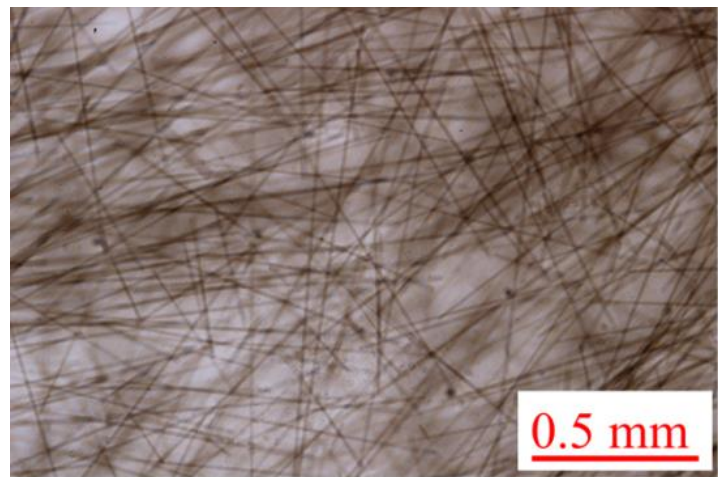

(b) BF5;

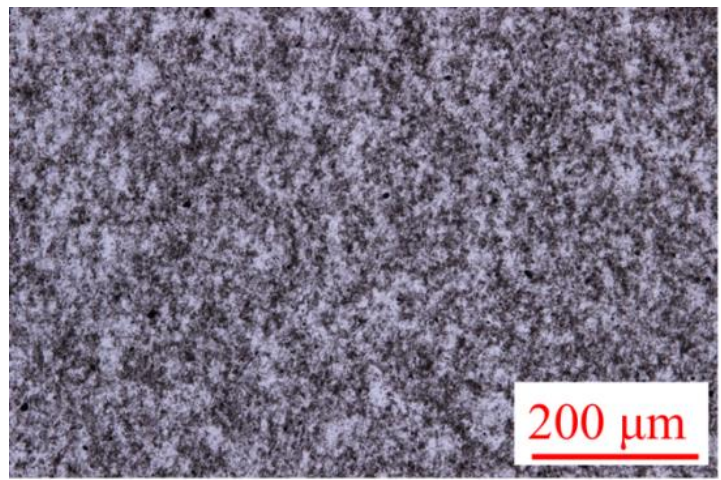

(d) MWCNT0.3 


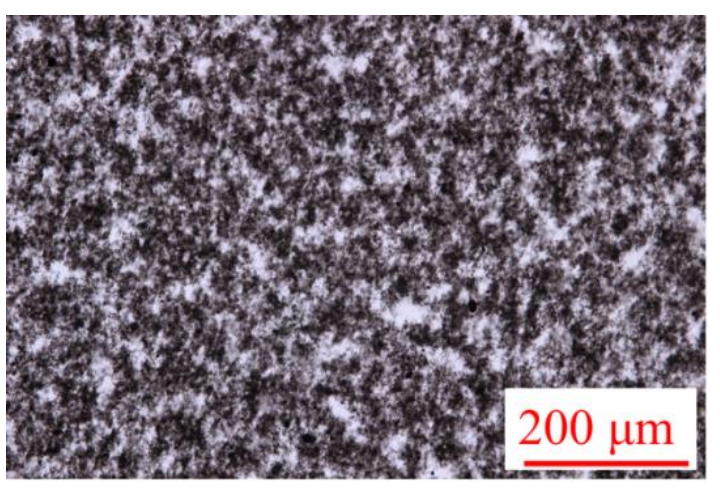

(e) MWCNT0.5

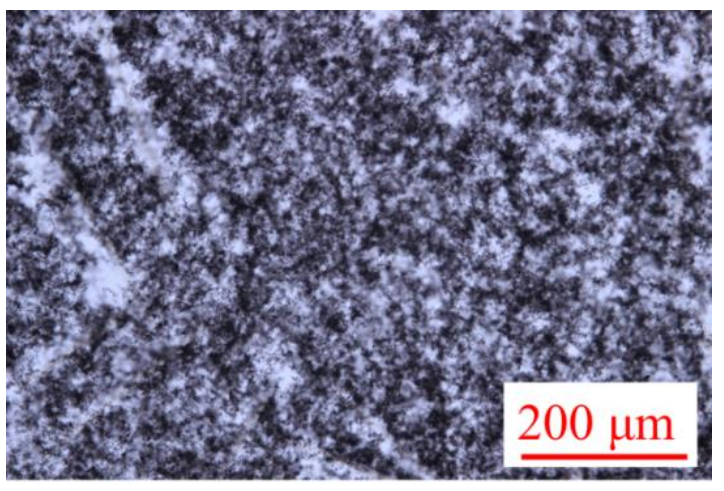

(g) BF5-MWCNT0.3

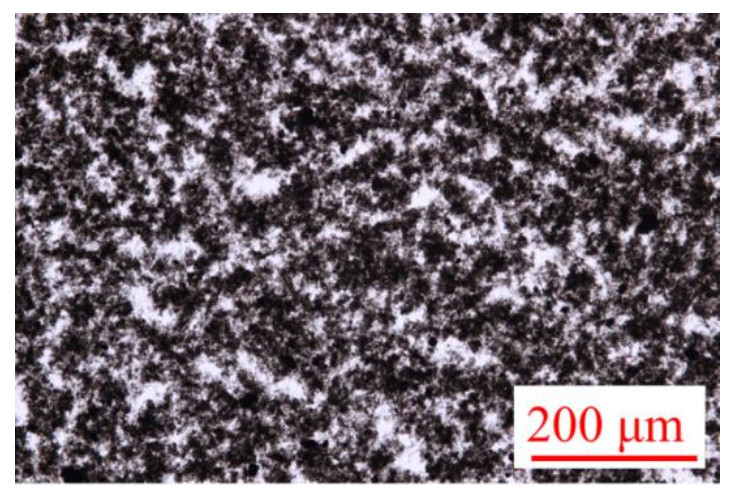

(f) MWCNT0.8

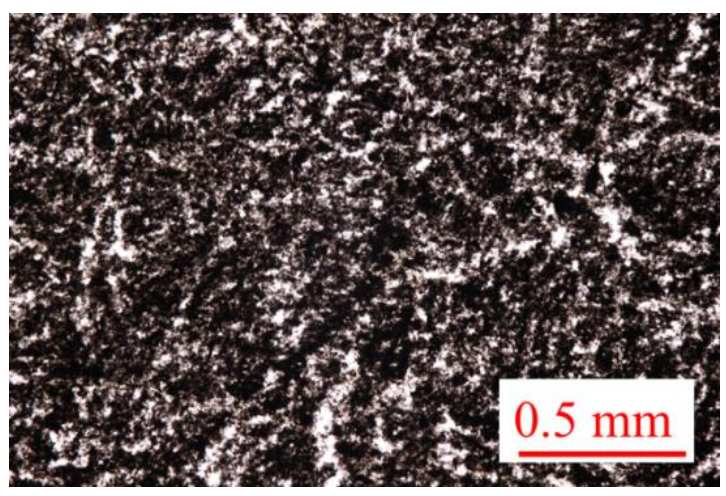

(h) BF5-MWCNT0.5

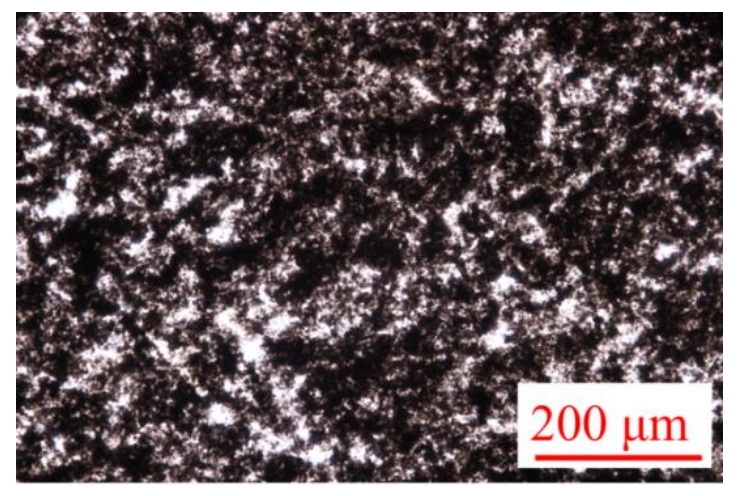

(i) BF5-MWCNT0.8 
FIGURE 3 A typical SEM micrograph of MWCNTs collected after removing epoxy matrix, and the inset is a schematic showing the measurement of the length of a curved MWCNT.

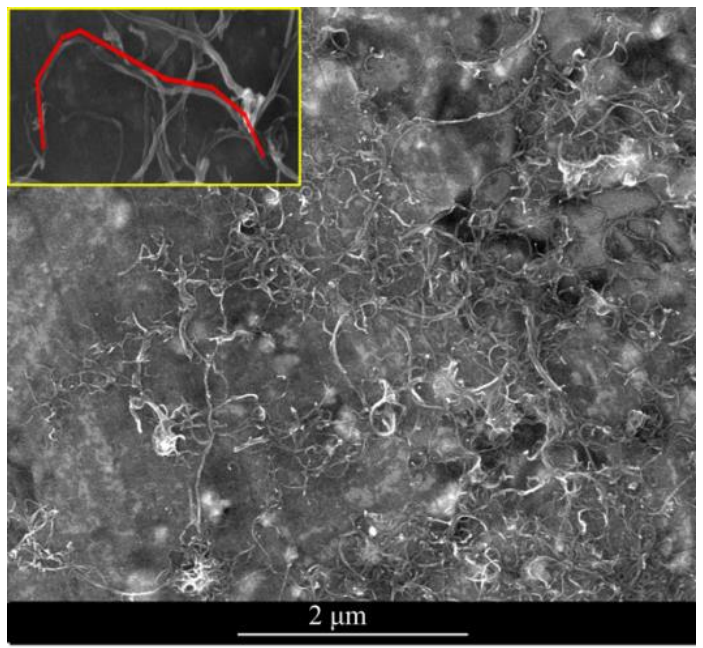

FIGURE 4 (a) Representative optical microscope images of the single fibre fragmentation test samples under polarised light, and (b) the IFSS between the BFs and the epoxy matrix.
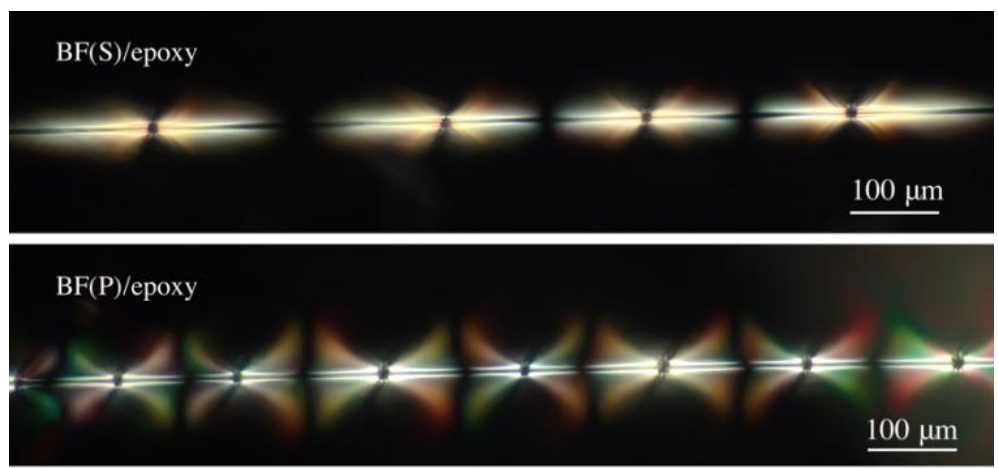

(a) Representative optical microscope images of the fragmentation samples

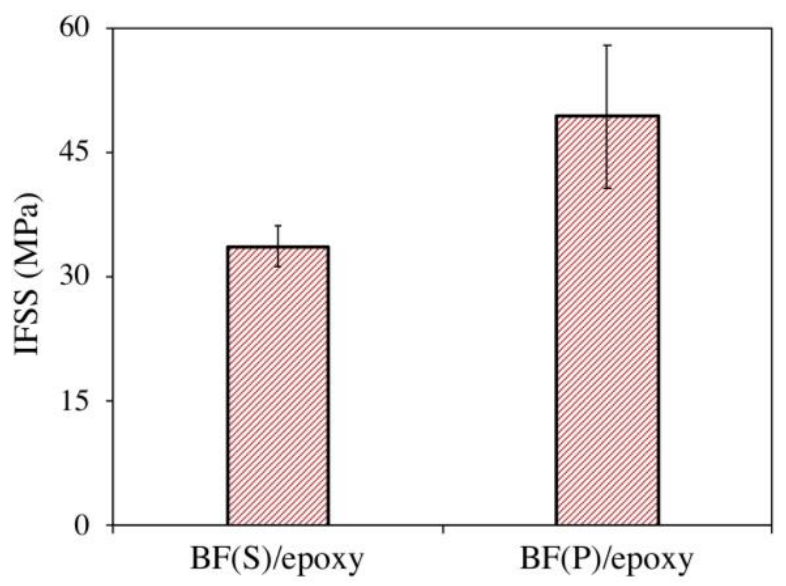

(b) IFSS between the BFs and the epoxy matrix 
FIGURE 5 Mechanical properties of the epoxy composites.

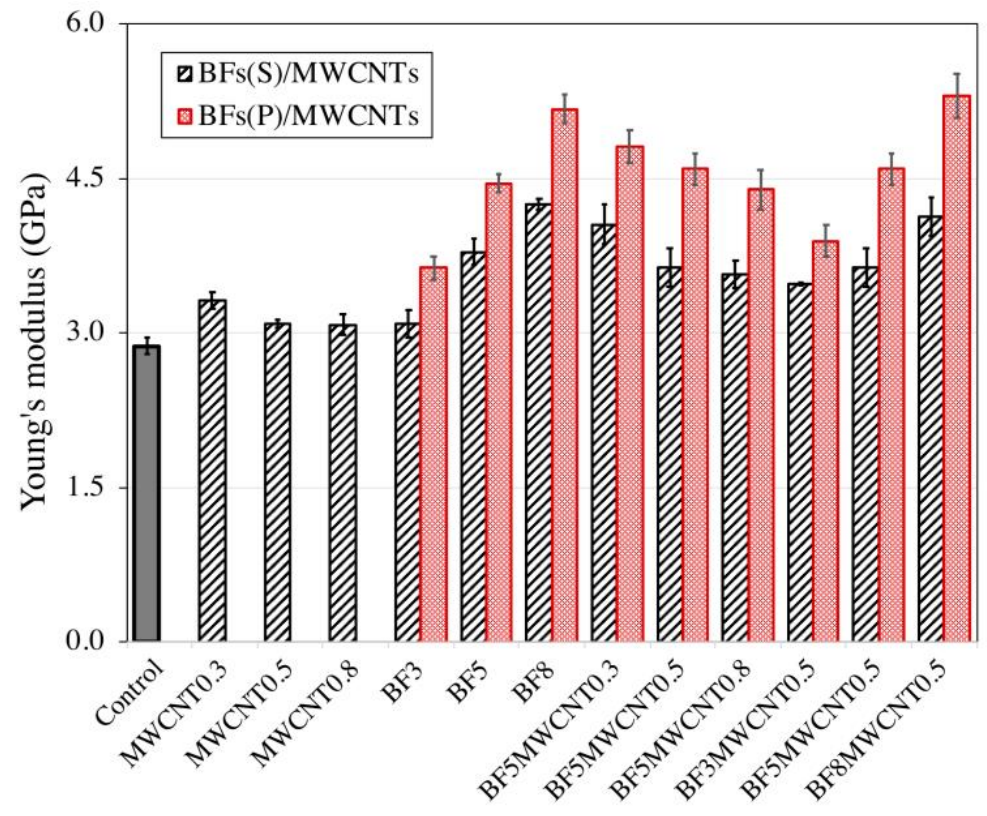

(a) Young's modulus

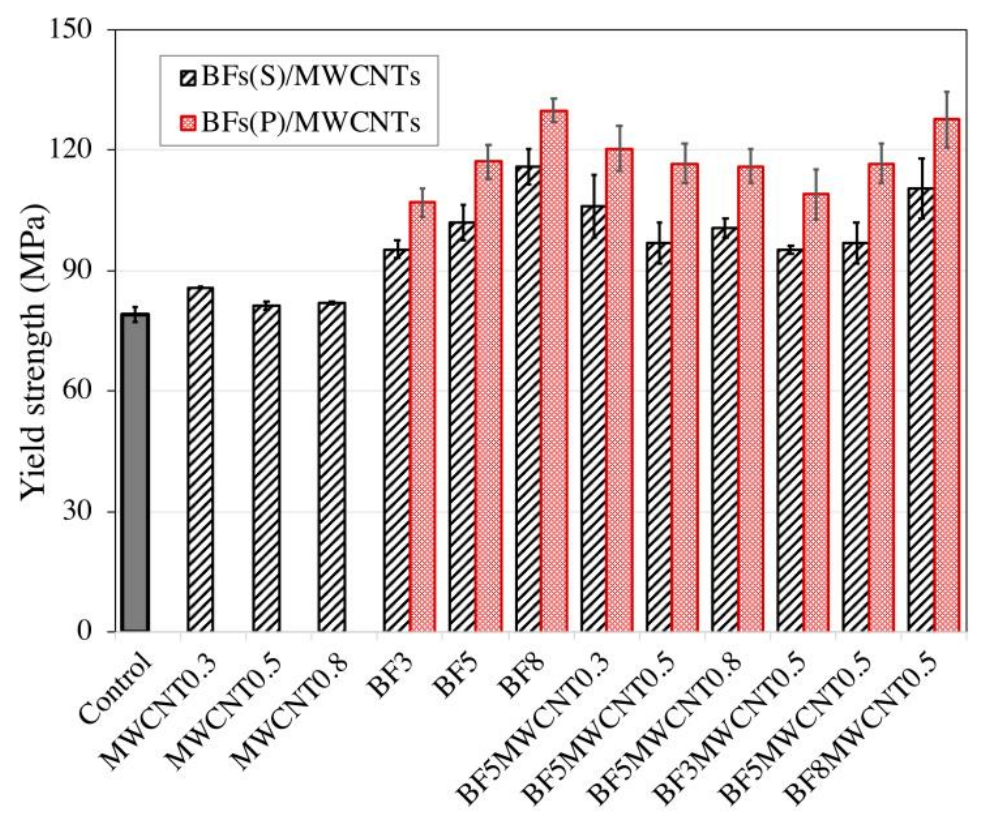

(b) Yield strength 
FIGURE 6 Fracture energy of the epoxy composites.

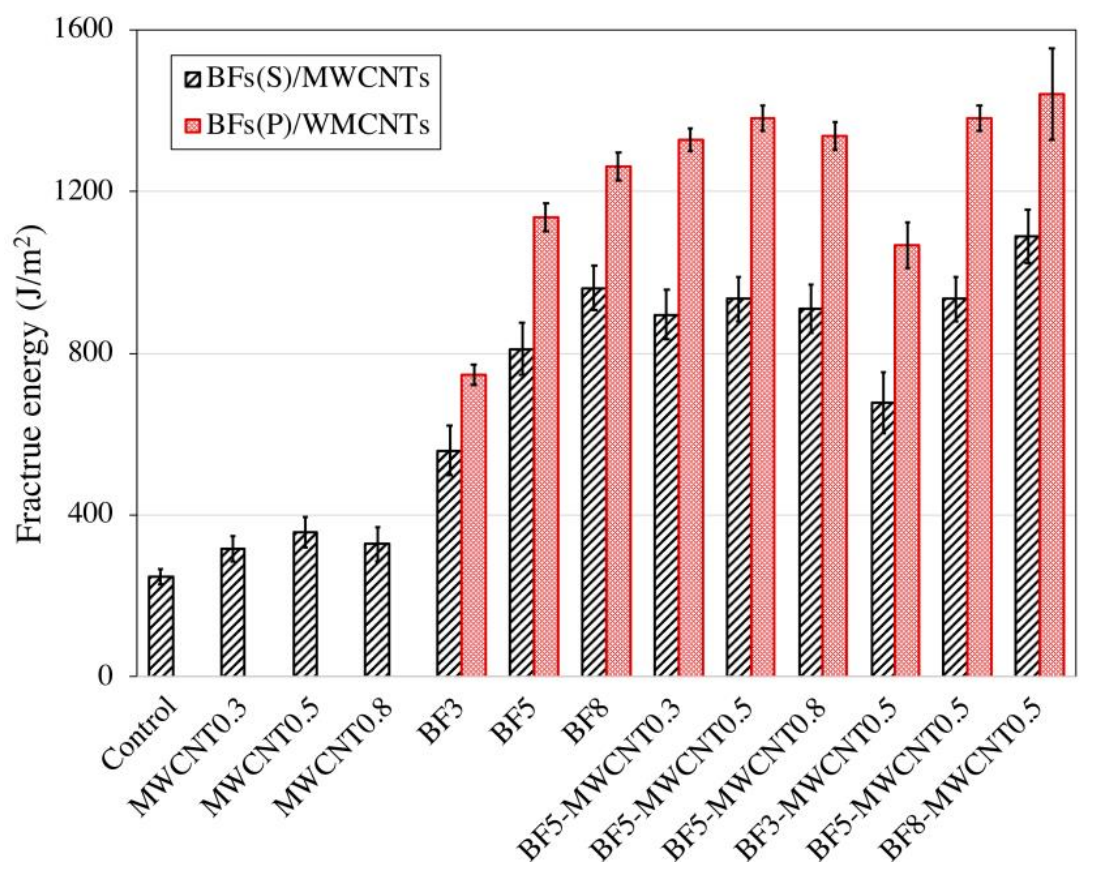

FIGURE 7 The difference between the toughness improvements of the hybrid composites and the composites containing solely BFs and MWCNTs.

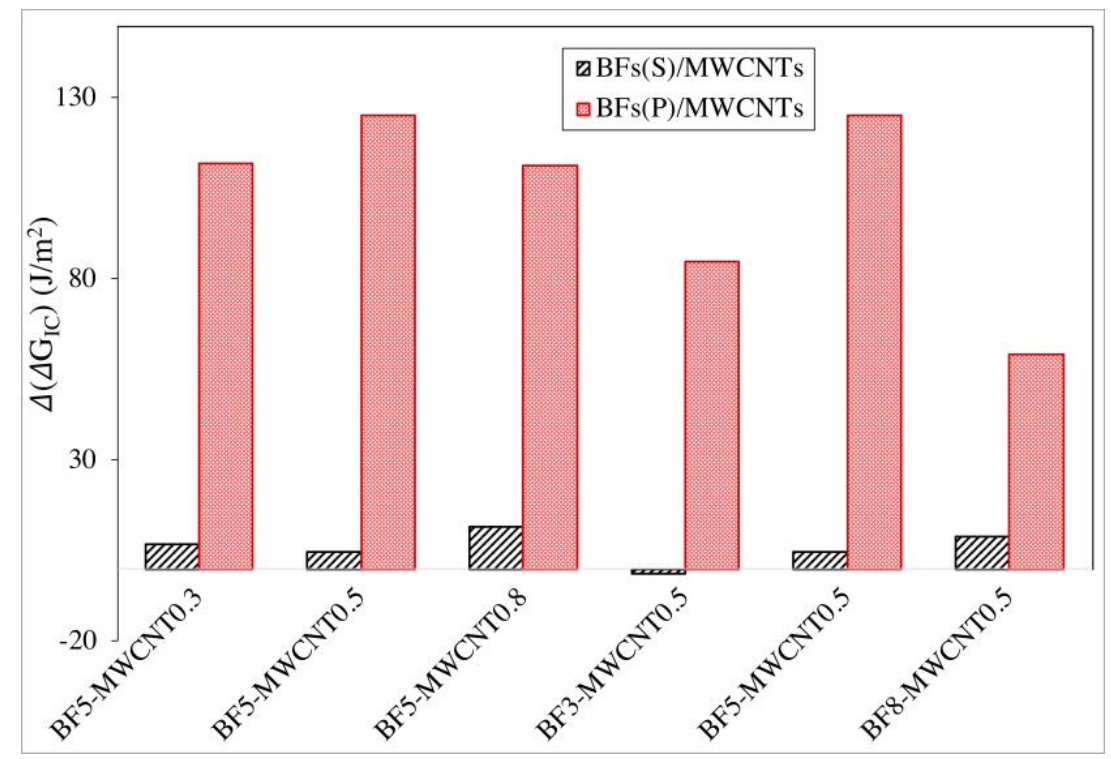


FIGURE 8 Micrographs of the fracture surfaces of the 3PB specimens. The red arrow indicates the crack growth direction. The red dashed line indicates the tip of the precrack.

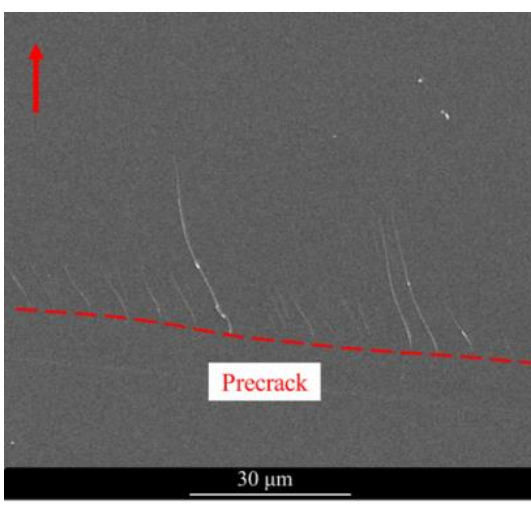

(a) Control

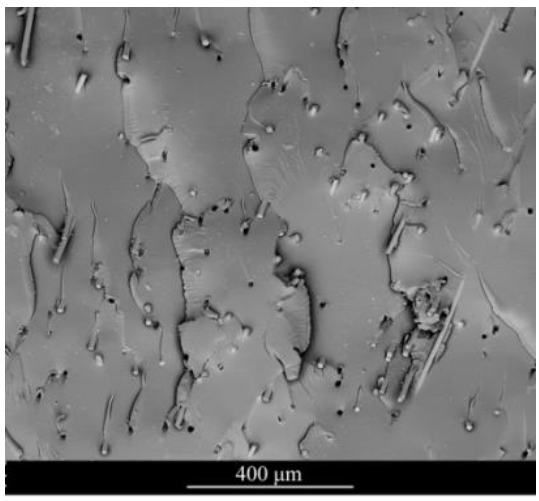

(d) $\mathrm{BF}(\mathrm{S}) 5$

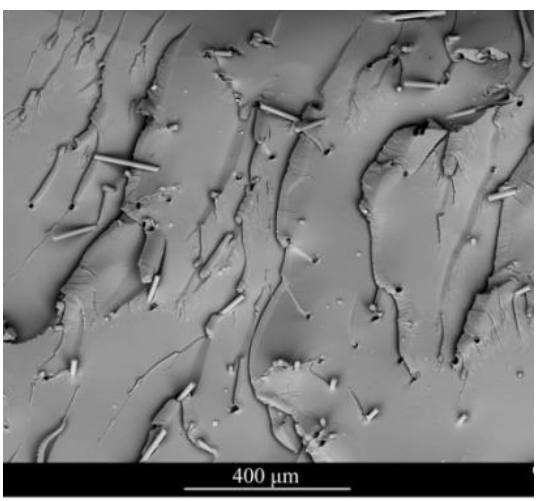

(g) $\mathrm{BF}(\mathrm{P}) 5$

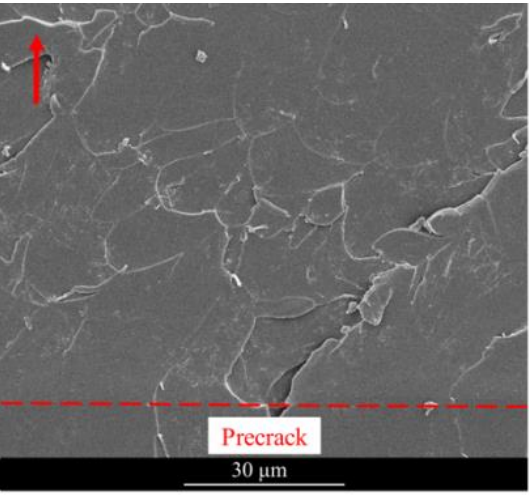

(b) MWCNT0.5

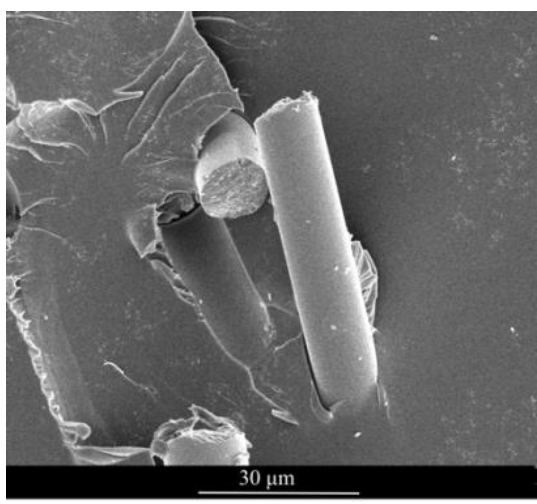

(e) $\mathrm{BF}(\mathrm{S}) 5-\mathrm{MWCNT} 0.5$

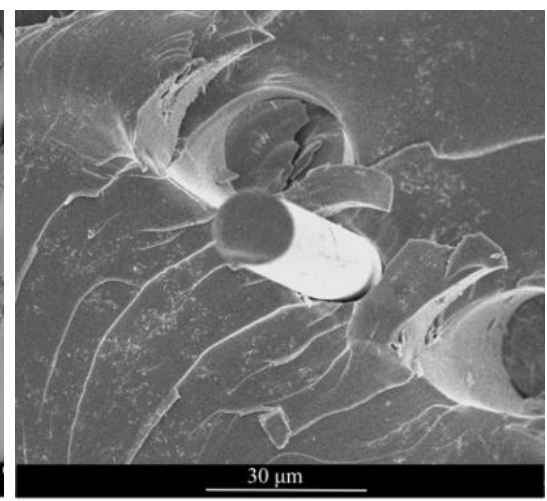

(h) $\mathrm{BF}(\mathrm{P}) 5-\mathrm{MWCNT} 0.5$

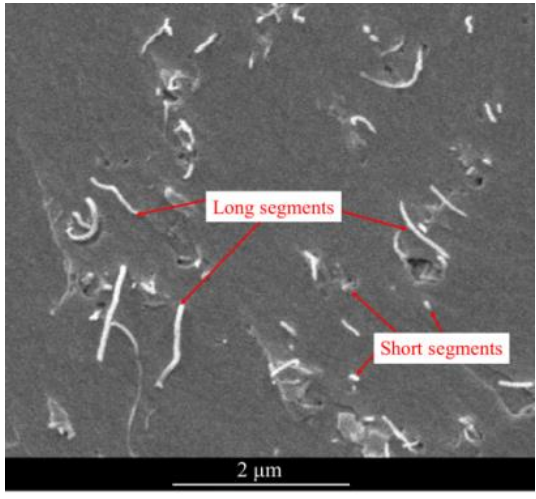

(c) MWCNT0.5

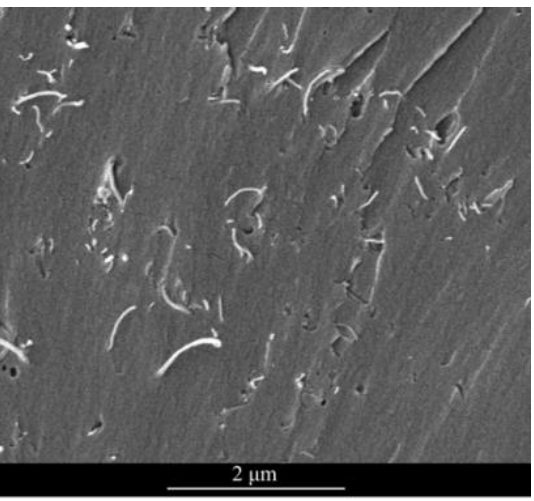

(f) $\mathrm{BF}(\mathrm{S}) 5-\mathrm{MWCNT0.5}$

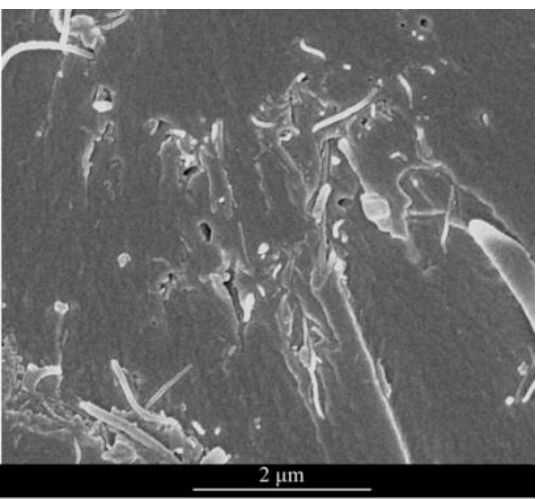

(i) $\mathrm{BF}(\mathrm{P}) 5-\mathrm{MWCNT} 0.5$. 
FIGURE 9 A schematic of the toughening mechanisms of the short BFs. The red line indicates the crack growth path.

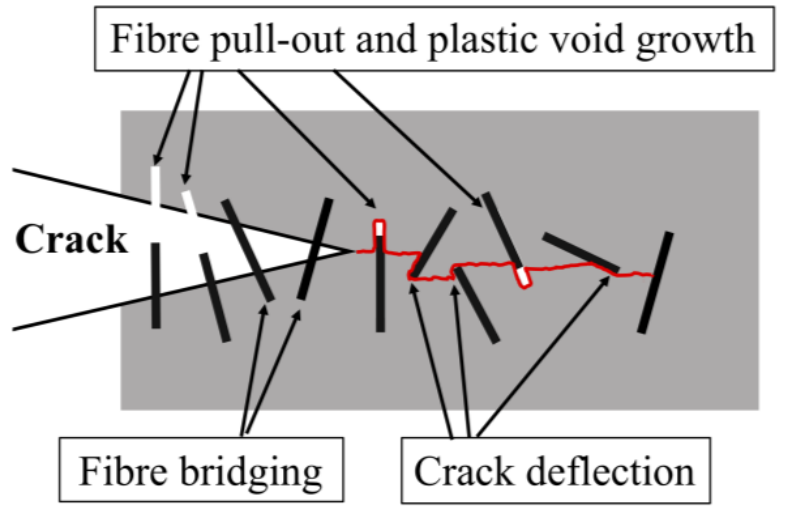

FIGURE 10 The electrical conductivity of the epoxy composites.

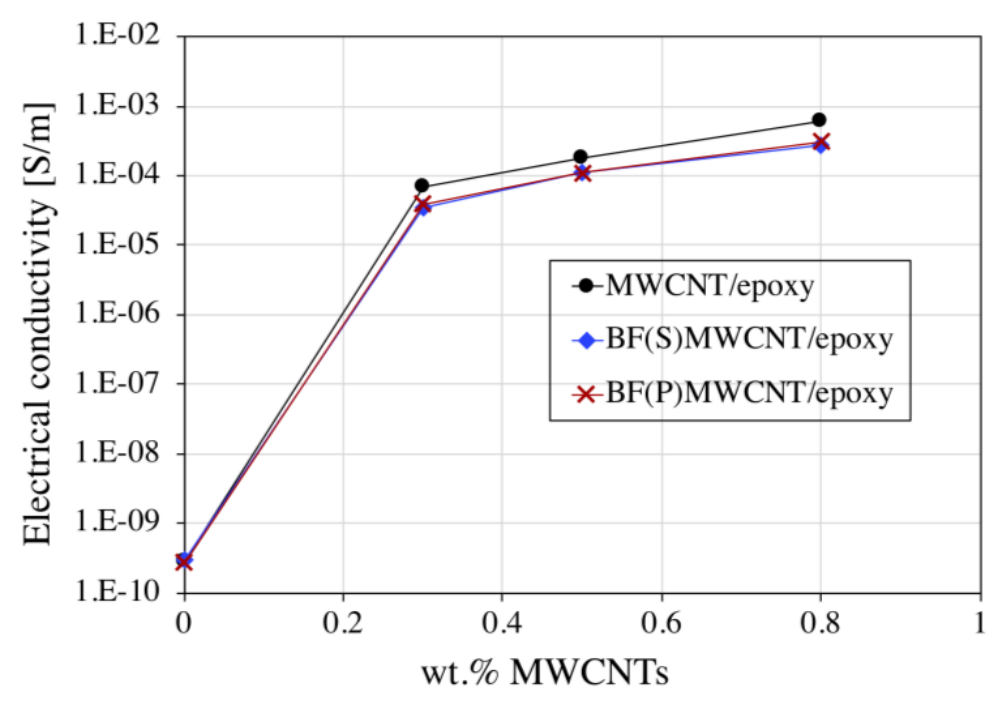

\section{TABLES:}

Table 1: Atomic \% of species on the surfaces of the BFs before and after the plasma treatment

\begin{tabular}{lcccccccc}
\hline & $\mathrm{C} 1 \mathrm{~s}$ & $\mathrm{O} 1 \mathrm{~s}$ & $\mathrm{Si} 2 \mathrm{~s}$ & $\mathrm{Al} 2 \mathrm{~s}$ & $\mathrm{Ca} 2 \mathrm{p}$ & $\mathrm{F} \mathrm{1s}$ & $\mathrm{N} 1 \mathrm{~s}$ & $\mathrm{C}: \mathrm{O}$ \\
\hline Before treatment & 81.49 & 16.36 & 1.23 & 0.16 & 0.14 & 0.62 & - & 4.98 \\
After treatment & 65.63 & 26.23 & 4.18 & 0.46 & 0.71 & - & 2.79 & 2.50 \\
\hline
\end{tabular}

